\title{
Nicaragua: \\ El camino de la derrota electoral y el porvenir de la revolución sandinista
}

\author{
Carlos M. Vilas'
}

...los que en la historia han tratado de sobrevivir haciendo concesiones, nunca han sobrevivido. ...el único camino de la supervivencia de los procesos revolucionarios es la resistencia.

Fidel Castro, 1990:183.

We made our speeches; we pounded the table; we demanded that the international community

support our cause. (...)

Well, we won; we got what we wanted.

Lawrence Eagleburger, 1990.

...es obvio que esos lazos externos no son gratis, que hay un precio que la Revolución Sandinista tendrá que pagar por ellos, y que recaerá ante todo en los trabajadores urbanos y rurales, vale decir en los mismos sectores que contribuyen físicamente

a la lucha contra la contrarrevolución.

Vilas 1986a: 128.

En las elecciones del 25 de febrero de 1990 la coalición Unión Nacional Opositora (UNO), con la tórmula presidencial Violeta Barrios de Chamorro-Virgilio Godoy, derrotó por un abultado margen de votos 
al Frente Sandinista de Liberación Nacional (FSLN) que buscaba la reelección de la fómula Daniel Ortega-Sergio Ramírez. La UNO obtuvo casi $55 \%$ de los votos en la elección para presidente y vicepresidente contra poco menos de $41 \%$ del FSLN y se aseguró la mayoría en la Asamblea Nacional con 51 de los 92 bancas, frente a sólo 39 del FSLN.

La derrota electoral del sandinismo frente a una coalición apoyada por el gobiemo de Estados Unidos dio paso a muchas interpretaciones que tratan de explicar 10 inesperado. El resultado se adjudica sobre todo a las agresiones militares y económicas que el gobiemo de Estados Unidos libró contra el régimen sandinista durante casi toda la década de 1980, con un impacto severo en la producción, la infraestructura, el abastecimiento, el empleo, el comercio exterior, los servicios sociales, las condiciones de vida de las masas, los miles de jóvenes muertos y mutilados.

Este autor concuerda con mucho de lo que se ha dicho sobre ésto -y también ha analizado otros factores intervinientes en los resultados: la cuestión de las candidaturas, el tipo de campana electoral conducida por el FSLN, etc. (Vilas 1990a) -, pero lo considera insuficiente. La guerra jugó un papel importante, pero más que directamente en el resultado de las elecciones, influyó en su efectiva configuración y en el modo en que ellas fueron encaradas por el sandinismo: como una dimensión del proceso más amplio de negociación regional que debería conducir al cese del apoyo norteamericano a la contra y al desarme de ésta, y a neutralizar preventivamente los argumentos del gobierno norteamericano que negaban contenido democrático al régimen sandinista y se preparaban a desconocer un triunfo electoral que los sandinistas consideraban más allá de toda duda.

El argumento que se desarrolla en este articulo es que la estrategia de negociación internacional aceptada por el gobierno sandinista, y las políticas económicas y sociales impulsadas desde mediados de 1988, contribuyeron de manera significativa a la derrota electoral, en un escenario de guerra contrarrevolucionaria en el cual la negociación internacional y el discurso y las políticas gubernamentales despojaron de contenido político y de clase al conflicto bélico. En estas condiciones, la idea de los anos iniciales de que los sacrificios impuestos por la guerra apuntaban a la defensa de las conquistas revolucionarias y que para ganar la guerra habia que movilizar a las masas en torno a esas conquistas, y no solamente movilizar a los soldados a los frentes de batalla, dio paso a un enfoque convencional de la guerra como enfrentamiento entre dos gobiernos, sin un contenido político de masas. Em- 
pantanada la revolución en la negociación intemacional, desvirtuadas muchas de sus banderas por la politica económica, la gente votó por el partido que daba mayores seguridades de paz, puesto que contaba con el respaldo explicito del contendiente más poderoso.

Este artlculo analiza los virajes de la política económica del sandinismo a partir de 1988 y los aspectos principales del proceso de negociación regional, y el impacto que unos y otro tuvieron en las caracteristicas generales del régimen revolucionario y en las condiciones de vida y la movilización de las masas. Se discute la existencia de altemativas a las polfticas económicas de ajuste, y en la última sección se explora el impacto del cambio de gobiemo en los asuntos internos de Nicaragua y en el futuro del sandinismo.

\section{Del camblo revoluclonarlo al ajuste estructural.}

El programa de transformaciones socioeconómicas encontró del sandinismo dificultades crecientes a partir de 1985 como resultado de una compleja conjugación de factores adversos que venían acumulándose desde inicios de la gestión revolucionaria: la oposición de sectores amplios de las clases propietarias y los grupos medios y la Intensificación de los conflictos sociales; las presiones económicas y políticas externas y el incremento de la guerra contrarrevolucionaria; los desfases y desajustes inherentes a todo proyecto de cambio social ocelarado (Vilas 1989.a).

Durante 1987 el incremento de la actividad militar y los demás factores sefalados ahondaron la desarticulación de la economía. Las exportaciones permanecieron en un valor casi $50 \%$ inferior al de inicios de la década. Las actividades de la especulación y mercado negro abarcaban todas las ramas de la economia. Una cuarta parte de la fuerza de trabajo estaba desempleada, y otro tanto bajo las armas. La inflación alcanzó valores de cuatro dígitos y el salario real, con base 1980 = 100, llegó a un nivel de 11; el endeudamiento externo se incrementó un tercio respecto del ano anterior, superando los 7,000 millones de dólares. La falta de mantenimiento, problemas de obsolecencia de equipos, y otros, agudizaron las limitaciones de la infraestructura: cortes de energía eléctrica, deterioro del sistema de transportes y comunicaciones, etc. Nicaragua ingresó en el proceso negociador de Esquipulas en condiciones de extrema vulnerabilidad económica y de relativa desmovilización de las masas, más notoria sin embargo en las ciudades que en el campo.

El programa de ajuste con que el sandinismo intentó encarar estos problemas en junio 1988 no fue un trueno en un día de sol, sino que 
venla siendo discutido en el seno del gobiemo por lo menos desde 1983 (Junta de Gobiemo de Reconstrucción Nacional 1983) y trató de ser ejecutado por primera vez, aunque de manera menos drástica, en febrero de 1985. Un mes después que Daniel Ortega asumió su mandato presidencial como resultado de las elecciones de noviembre 1984, se adoptó un programa de ajuste tendiente a fortalecer los ingresos gubermamentales y reducir el déficit fiscal (vid Barricada, 10 de febrero de 1985). Esto se consiguió en pequena medida, pero al precio de un incremento vertiginoso de la inflación, una mayor degradación de los abastecimientos básicos, el reforzamiento de las presiones espoculativas y un deterioro más agudo de los ingresos reales de los trabajadores (Vilas 1986b y 1989a). El programa fue dejado de lado ante la convicción de que sus efectos socioeconómicos en las masas podrian repercutir negativamente en el esfuerzo de guerra y minar adicionalmente las bases sociales del sandinismo. Además la guerra impedía reducir el principal nubro del gasto público: la defensa, que en 1986 absorbia $35.6 \%$ del presupuesto del gobiemo y en 1987 el $41 \%$.

La derrota militar de la contrarrevolución, que se hizo irreversible desde principios de 1988, la reducción del financiamiento que ella recibia del gobierno norteamericano, el avance del proceso de negociación regional a partir de Esquipulas II (agosto 1987), y la reducción de la actividad militar luego de la firma del acuerdo de Sapoá (marzo 1988) entre el gobiemo Sandinista y los contras, enmarcaron el lanzamiento de un nuevo y más drástico programa de ajuste a principios de junio 1988. El gobierno sandinista entendió que ya no existian los factores extraeconómicos que habrian podido transformar el impacto social del ajuste en un deterioro de sus bases políticas. "Sin duda - senaló un editorial del diario Barricada al promediar la ejecución del programa- las condiciones político-militares ahora favorecen las políticas de estabilización" (30 de enero 1989).

Se decretó una macro devaluación que sería continuada por otras de parecida magnitud en agosto, septiembre y diciembre, y durante 1989. se inició una política de indización de las tarifas de los servicios públicos y el crédito de acuerdo a la evolución del índice de precios minoristas y a la evolución de los precios centroamericanos; se aumentaron los incentivos en divisas convertibles a los exportadores, se eliminó la mayoria de los controles de precios y de comercialización al mismo tiempo que se fortalecieron los controles sobre la masa salarial; se promovió una reducción adicional del salario real y del consumo, apelándose asimismo al sistema convencional de racionamiento a través de los precios en detrimento del sistema anterior, ya muy deteriorado e ineficiente, de racionamiento vía cuotas. La contracción del 
gasto público y la reducción del empleo en el gobiemo central afectaron a los servicios sociales y a los programas de desarrollo, sobre todo en las que hablan sido zonas de guerra, y en la Costa Arlántica.

La paz permitió cortar los gastos de defensa; en 1989 el presupuesto del ejército se redujo en $29 \%$ y el de las fuerzas de seguridad en más de $30 \%$. La reducción de la inversión pública se efectuó al costo de fortalecer en el corto plazo los factores recesivos de la economia, elevar los ya altos niveles de desempleo de la fuerza de trabajo, y deteriorar adicionalmente las condiciones de vida de las masas. EI enorme costo social de esta estrategia fue reconocido por el gobiemo sandinista, que lo juzgó una injusticia necesaria. ${ }^{2}$ Se redujeron los controles económicos de los anos anteriores, se apeló de manera esperanzada a los mecanismos del mercado para la reactivación de la economia y se intentó la reprivatización de algunas empresas estatales. A principios de 1989 casi 50\% del personal de la Secretarla de Planificación y Presupuesto fue cesanteada o transferida a otras agencias del gobierno.

En un ambiente económico de retracción casi absoluta de la inversión privada, la inversión pública se redujo más de $66 \%$ entre 1987 y 1989, el empleo público disminuyó en unas 50,000 personas (casi $20 \%$ de la nómina del gobiemo central), y la tasa abierta de desempleo llegó a $28 \%$ a principios de 1989 . La eliminación de los subsidios impactó inmediatamente en los precios y en la estructura de costos. Apenas una semana después de iniciado el programa, el diario Barricada del FSLN informó por ejemplo de una fuerte reducción de la venta carnes, frutas y legumbres en los mercados de Managua y de la pérdida de esos productos por esa causa (edición del 27 de junio 1988). Entre enero y febrero de 1989 el precio del transporte público urbano auménto en 25 veces.

La estrategia sandinista original de agroexportación y seguridad alimentaria con transformaciones socioeconómicas fue reemplazada por un enfoque convencional de agroexportación sobre la base de costos laborales comprimidos y reversión parcial de algunas de aquellas transformaciones. El enfoque adoptado en junio 1988 y reforzado en enero 1989 tuvo muchas de las caracteristicas de la condicionalidad que el FMI y el Banco Mundial imponen a los palses que solicitan sus fondos para encarar desajustes económicos. Lo novedoso del caso nicaragũense es que el programa fue adoptado unilateralmente por el gobiemo sandinista y sin la provisión de fondos que es la contrapartida de los programas de ajuste auspiciados por esas instituciones. Si el enfoque del FMI es "fondos con condicionalidad", el enfoque sandinista 
fue "condicionalidad sin fondos" (Vilas 1989a pág. 112). Sin acceso a fondos liquidos externos -que la comunidad socialista no podia ofrecer-, el gobierno sandinista apeló a los programas de ajuste pensando en ellos también como llaves que abririan las puertas de Europa Occidental a divisas de libre convertibilidad (Vilas 1989c).

La estrategia se adoptó en el marco de fuertes tendencias recesivas, y las agravó, combinando niveles crecientes de precios con niveles decrecientes de actividad: inflación monetaria y deflación real. El índice de precios al consumidor, que habia crecido $134 \%$ en 1987 , aumento casi $33,000 \%$ en 1988 , mientras el PIB por habitante que habia caido $3.9 \%$ en 1986 y $1.7 \%$ en 1987 , se redujo $12.1 \%$ en 1988 ; los fondos externos no llegaron. El deterioro de los salarios fue brutal, a partir de una evolución negativa que venía registránodose durante toda la década. De acuerdo al enfoque monetario convencional, los salarios constituyen el colchón que permite operar a las políticas de estabilización y ajuste. A fines de 1988 el salario real habia decendido a un nivel 5 tomando como base $1980=100$, con un deterioro real de más de $50 \%$ durante 1988; en algunas ramas de la industria representaba menos de $5 \%$ de los costos de producción, y en el gobierno central alrededor de 9\% (APEN 1988; Pilarte et al 1988). De una manera distinta a la que imaginó Marx, el sandinismo consiguió la abolición de los salarios.

Los precios pagados a los productores de granos básicos -es decir a los campesinos - también quedaron rezagados respecto del índice general de precios, convirtiéndose en otro colchón para la operatividad de la estrategia de ajuste. El retraso de los precios de las mercancias que produce, combinado con el crecimiento exponencial de los costos de producción y del crédito por las devaluaciones y la indización de las tasas de interés, significó un deterioro fuerte de la posición de ingresos de los pequenos y medianos productores rurales, y un endeudamiento enorme. De acuerdo a un informe oficial, a principios de 1989 se pagaban en Nicaragua los precios a productores de granos básicos más bajos de Centroamérica (CIERA 1989). ${ }^{3}$

El impacto de las políticas de ajuste también fue muy fuerte en la pequena producción industrial, que con $40 \%$ de los establecimientos generaba en 1988 alrededor de $25 \%$ del producto manufacturero. EI encarecimiento de los insumos, las restricciones crediticias y el alza de la tasa de interés, la abultada presión impositiva, y la retracción del consumo interno, golpearon severamente al sector, que ya venía experimentando problemas serios. En la Regió IV por ejemplo (departamentos de Granada, Masaya, Carazo y Rivas) de 152 cooperativas industriales registradas a principios de 1988 quedaban produciendo so- 
lamente 82 en abril 1989, y de 20 cooperativas textiles, solamente dos.

Asalariados, campesinos y pequehos productores debieron asumir el costo social de las políticas de ajuste: es decir, las que en la terminologia de los anos iniciales eran llamadas fuerzas motrices de la revolución. La recomposición de las finanzas públicas y de la rentabilidad empresarial fue subsidiada por la reducción de los ingresos de estos sectores. Es importante recordar que también fueron ellos los que corrieron con lo principal de los costos sociales de la guerra. Ellos fueron, en efecto, los grupos sociales que aportaron al grueso de los combatientes del EPS y de la contra, los que pusieron los muertos y los heridos, los mutilados, los desplazados, los secuestrados. Y cuando la guerra termino, debieron pagar los platos rotos.

Durante 1988 el consumo de leche se redujo en casi $50 \%$, y el de azúcar $40 \%$. Enfermedades como tuberculosis y malaria se extendieron de manera notoria; la diarrea infantil incrementó su cuota de ninos muertos. De acuerdo a estimaciones del Ministerio de educación 30\% de la población adulta del departamento de Managua era analfabeta a fines de 1988, al mismo tiempo que los becarios que regresaban del exterior después de cinco y seis anos de estudios superiores no encontraban trabajo por la contracción de la producción, y la Juventud Sandinista les aconsejaba que no regresaran, o que se fueran al Africa o al Medio Oriente. Las medicinas se apilaban en los depósitos del Ministerio de Salud porque la gente no podia comprarlas por sus precios elevados, hasta el punto que periódicamente se regalaban las que estaban a punto de vencerse (Barricada 15, 20 y 21 de febrero, y 13 y 27 de abril, 1989; El Nuevo Diario, 27 de abril 1989).

\section{Del ajuste económico al ajuste polítlco y soclal.}

El mayor énfasis en los mecanismos de mercado involucró una nueva aproximación del gobierno hacia los grandes productores privados. Se ampliaron los incentivos en dólares-, se renovaron las garantias a la propiedad privada y se proclamó el fin de la reforma agraria. Una declaración similar se habia efectuado a fines de 1984 con la finalidad de apaciguar los temores de los grandes productores después de las elecciones de noviembre de ese ano. Lo novedoso ahora fue la apropiación del lenguaje de las élites por los dirigentes sandinistas: el viceministro de la reforma agraria anunció el fin de las "confiscaciones", el nombre empleado por la oposición burguesa para referirse a lo que la ley de reforma agraria denomina, técnicamente, "afectaciones" (vid Barricada, 2 de febrero 1989). Varias fincas que habian sido adjudicadas a cooperativas campesinas fueron entregadas por MIDINRA a grandes pro- 
ductores privados, y las cooperativas fueron desmanteladas o forzadas a desplazarse a tierras marginales; las protestas de la UNAG no recibieron respuesta satisfactoria del Ministerio. Durante la campana electoral el presidente Daniel Ortega, buscando su reelección, aseguró a los terratenientes de la región IV afectados por la reforma agraria que serán compensados con la devolución de sus propiedades, maquinarias y otros bienes" (Barricada, 14 de diciembre 1989).

La política económica estuvo rodeada de una retórica que hirió ideobógicamente a los que perjudicaba económicamente al mismo tiempo que continuaba las concesiones a los grupos acomodados. Cuando los obreros de la construcción y de la mecánica automotriz se declararon en huelga en demanda de mejoras salariales, la respuesta del gobierno fue acusarlos de estar al servicio del gobierno de Estados Unidos y lanzarles la policia; cuando los maestros y los trabajadores de salud reclamaron mejores salarios al presidente Ortega, éste les endilgó un discurso sobre sus obligaciones morales respecto de la población y les reganó por su condición de trabajadores no productivos (Barricada, 18 y 19 de junio 1988), y cuando un ano después algunos sectores del magisterio declararon, por los mismos motivos, la huelga, sobrevino la usual acusación de estar al servicio de los Estados Unidos y de contribuir a la espiral inflacionaria (Barricada, 22 de mayo 1989). Cuando las cooperativas de producción industrial reclamaron por las altisimas tasas de interés y la carga impositiva, el ministro de Finanzas les contestó que a menos que se ajustaran a la nueva política, muchas de esas cooperativas tendrian que "desaparecer irremediablemente" (Barricada, 30 de junio 1988), como efectivamente ocurrió.

Pero dos dias después de la condena a muerte a los pequenos industriales, el "Pacto de Boaco" celebrado entre los grandes ganaderos de los departamentos de Boaco y Chontales, MIDINRA, y el Banco Nacional de Desarrollo, estableció que las deudas contraidas por los primeros quedarian al margen de la indización y podrian ser pagadas de acuerdo a sus valores nominales (Barricada, 2 de julio 1988). Menos de un ano después la asamblea del MIDINRA con empresarios, campesinos y obreros del campo en el marco de la denominada política de concertación (20 de abril 1989), en la cual el gobierno aprobó un subsidio de un millón de córdobas por manzana (equivalente a unos 150 dolares) a los algodoneros -que to habian solicitado- y rechazó la demanda obrera de un salario que cubriera como minimo una canasta de ocho productos básicos.

La reducción del empleo público a través de cesantias masivas fue encarada de manera vertical y burocrática, sin participación de las or- 
panizaciones sindicales ni de los propios involucrados. Se prestó por lo lanto a un címulo de arbitrariedades e injusticlas, y afectó mucho más a los trabajadores que a los funcionarios. En muchos casos resultaron afectadas personas que se encontraban con permiso por enfermedad, o movilizadas en el servicio militar, o mujeres en uso de licencia maternal.

Se reforzó asimismo el estilo particularista y prebendalista de ejercicio del poder político: un estilo que el sandinismo no inventó y que se inscribe en lo más profundo de las tradiciones políticas nicaragūenses, pero que tampoco contribuyó a erradicar y muchas veces contribuyó a reproducir. El deterioro generalizado de las condiciones de vida de la gente hizo más notorias e irritantes las desigualdades derivadas del acceso a amistades, a posiciones en el estado y a favores. En algunas ocasiones el gobierno administró este acceso particularista a condiciones de vida más holgadas como un medio de retener a técnicos y profesionales en el sector público compensando los salarios increfblemente bajos. En el fondo, era como crear un mercado de valores políticos en reemplazo del mercado convencional de valores económicos - fuerza de trabajo, salarios, bienes y servicios-, pero más frecuentemente se trató de la reproducción de los estilos políticos tradicionales para los cuales el ejercicio del poder conlleva el acceso a beneficios sociales y materiales. Una cuestión para cuya comprensión Max Weber resulta más útil que Marx (Vilas 1987). ${ }^{5}$

El viraje de las políticas económicas creó problemas a las organizaciones populares sandinistas, que quedaron aprisionadas entre su lealtad politica al FSLN, que las llevaba a justificar y defenser el nuevo enfoque, y la lealtad a sus bases sociales, golpeadas por el ajuste y su distribución desigual de premios y sinsabores. El resultado fue una disminución de la capacidad de reclutamiento y movilización y una disminución de los niveles de participación y activación populares, que algunos veniamos observando desde anos anteriores (Vilas 1986c). La desmovilización popular es tanto un efecto de las políticas de ajuste cuanto una condición para su viabilidad.

En sintesis, a partir de mediados de 1988 el gobierno sandinista encaró una política económica que favoreció a los ricos y perjudicó a los pobres, y que además los agredió ideológicamente y ratificó en el discurso oficial la ausencia de un espacio legítimo para buena parte de las bases sociales del sandinismo. Con el agravante que las concesiones efectuadas a los primeros, y que éstos aceptaban siempre demandando más, no alteraron su comportamiento político. En estas condiciones, las referencias a una orientación socialista del régimen sandinista, pre- 
cisamente en momentos en que el viraje hacia la derecha era más notorio, resultaron ser una curiosidad semántica que conmocionó a pocos."

En su afán por ganarse los votos de los empresarios y las simpatlas de abunos elementos del establishment polftico norteamericano, el discurso sandinista trató de desembarazarse de las reverberaciones revolucionarias del pasado. La guerra fue presentada como un enfrentamiento convencional entre dos estados, despojando al conflicto de su contenido ante todo político y social. En su largo discurso a la Asamblea Nacional el 30 de enero 1989 el presidente Ortega se refirió a la guerra como causa de la crisis económica; mencionó como antecedentes históricos a las Cruzadas y a la segunda guerra mundial, omitiendo en cambio toda mención a las dos grandes guerras revolucionarias de liberación nacional del siglo $X X$ que contribuyeron a forjar en las décadas de 1960 y 1970 las concepciones sandinistas de la guerra popular: China y Vietnam (Barricada, 31 de enero de 1989).

La nueva aproximación a los grandes empresarios fue encarada no solamente como estrategia de reactivación económica sino asimismo como una condición para acelerar el desarme y desmovilización de la contra y mejorar la imagen extema del sandinismo. En el escenario intemacional que se comenzó a montar tras la salida de Ronald Reagan de la Casa Blanca, los vientos de glassnost y perestroika soplando desde la Unión Soviética, y las numerosas iniciativas y presiones de organismos internacionales y gobiemos latinoamericanos para alcanzar la paz en Centroamérica, el encuentro de presidentes centroamericanos en Costa del Sol (El Salvador) reconoció la voluntad del gobierno de Nicaragua de poner fin cuanto antes a la cuestión de los ex guardias somocistas y de los gnupos contrarrevolucionarios que se mantenian en campamentos en territorio de Honduras, y de "desarrollar un proceso de democratización y reconciliación nacional... en el marco de los Acuerdos de Esquipulas II".

Un punto importante de las negociaciones en Costa del Sol fue la decisión de la diplomacia sandinista de adelantar las elecciones que debian efectuarse en noviembre 1990, "a más tardar al 25 de febrero" de ese ano. Esta fue una cuestión en la que algunos congresistas del Partido Demócrata habian insistido mucho para evitar una superposición de las elecciones nicaragūenses con las que deberán celebrarse ese mismo mes en Estados Unidos; el argumento de los norteamericanos fue que sería mucho más fácil para ellos presionar por el desalzamiento de los contras y por la reducción del financiamiento, y oponerse a la decisión de la Casa Blanca de renovar en mayo el embargo 
omercial contra Nicaragua, si para entonces los sandinistas ya hablan fectuado las elecciones - que de todos modos iban a ganar fácilnente. También hablan presionado en favor del adelantamiento de las lecciones varios de los presidentes latinoamericanos y el jefe del goiemo espanol, participantes con Daniel Ortega en los actos de asunión de Carlos Andrés Pérez a la presidencia de Venezuela (Caracas zbrero 1989). Se convino también en Costa del Sol la invitación a bservadores intemacionales para el proceso electoral, la reforma a la yy de medios, y la reestructuración del Consejo Supremo Electoral

Por primera vez en la breve historia de las negociaciones de paz en ientroamérica, el documento de los cinco presidentes dejó de lado el rincipio de simultaneidad en el cumplimiento de los acuerdos, expllitamente establecido en Esquipulas $\| \rightarrow$ vale decir, que los cinco obiemos debian dar cumplimiento a los convenios al mismo tiempo-, redujo la "cuestión centroamericana" a la cuestión nicaragũense". Una emana más tarde el presidente Ortega anunció en Managua, ante el stupor de la gente reunida en la Plaza de la Revolución, la decisión le indultar a unos 1,200 ex miembros de la Guardia Nacional somoista, que se encontraban cumpliendo condenas en cárceles de Nicaagua. A principios de 1990, en visperas de las elecciones, se amplió el rdulto a la totalidad de los ex guardias nacionales y a los miembros de 1 contrarrevolución que se encontraban cumpliendo condenas juiciales por violaciones a los derechos humanos.

El gobierno sandinista adoptó estas medidas después de haberse esistido a ellas durante anos, y aunque las presentó ante la población omo precios que habia que pagar por la desmovilización de la contra la paz, para mucha gente fueron pruebas de debilidad y de retroceso. in particular, la libertad concedida a los guardias somocistas subestimó I profundo antisomocismo persistente en amplios sectores de la polación nicaragūense, para quienes resultaba más comprensible el inulto a un ex contrarrevolucionario - que podia apelar al argumento de ue habia combatido al sandinismo porque éste se habia convertido al lotalitarismo" o al "comunismo", o porque la contra to habia secuesado- que el perdón a los ex guardias nacionales - "la genocida", en I lenguaje popular nica.

Lo que el sandinismo quería proyectar como imágenes de fuerza y e madurez, llegaba a la gente como mensajes de debilidad y oporunismo. Lo que para el FSLN y la opinión pública internacional eran vances de democratización, para las masas eran más bien retrocesos. lo en lo atinente a la cuestión electoral, que de todas maneras ya eszba contemplada en la constitución, pero si en lo atinente a las con- 
cesiones del sandinismo a las fuerzas politicas de la derecha regional e intemacional. Asl, al mismo tiempo que el sandinismo se presentaba como "una verdadera escuela" para América Latina Ramírez 1988, y de manera más elaborada Nunez \& Burbach 1987), los niveles de apatla política y de desmovilización de masas se hacian más notorias.'

El proceso centroamericano de negociación llevó al gobiemo sandinista, y éste aceptó ser llevado a eso, a concesiones igualmente sorprendentes en materia de política regional. En la reunión de Tela (Honduras) del 5 al 7 de agosto de 1989, el presidente Ortega se sumb a sus colegas de la región en instar "vehementemente al FMLN a un cese de hostilidades inmediato y efectivo, para realizar un diálogo que conlleve al abandono de la lucha amada y a la incorporación de los integrantes del FMLN a la vida institucional y democrática", sin que similar exhortación se hiciera a la Resistencia Nicaragūense (contras) que mantenian su actividad militar a pesar del cese al fuego unilateralmente declarado por el gobiemo de Nicaragua. En la siguiente cumbre presidencial en San Isidro Coronado (Costa Rica) el 12 de diciembre de 1989, Daniel Ortega adirib al pleno respaldo de sus colegas al presidente salvadoreno Alfredo Cristiani y a la condena al FMLN y su reciente ofensiva militar; como contrapartida obtuvo de los demás presidentes el reclamo para que la contra concluyera el proceso de desmovilización a más tardar el 5 de febrero 1990. Es sabido que este reclamo no obtuvo eco ni de los contrarrevolucionarios ni del gobiemo de Estados Unidos, pero el repudio al FMLN alinéo a Nicaragua con las posiciones más conservadoras respecto de la cuestión salvadorena. EI documento no hizo mención alguna al bombardeo de población civil por la aviación del gobierno salvadoreno, ni a la masacre de la dirigencia sindical de FENASTRAS, ni al asesinato de los sacerdotes jesuitas, y exigió al FMLN la renuncia unilateral a las acciones militares.

La firma de Ortega en este documento causó estupor y desconcierto en amplios sectores de la población nicaragūense, e incredulidad en la oposición. La solidaridad con el proceso revolucionario salvadoreno había constituido una de las líneas más conocidas de la diplomacia sandinista y uno de los puntos de conflicto con el gobiemo de Estados Unidos. La consigna "Si Nicaragua vencib, El Salvador vencera" habia sido coreada durante toda la década en los actos de masas y las movilizaciones populares. La primera propuesta del FDR-FMLN para el establecimiento de negociaciones directas con la entonces Junta de Gobierno de El Salvador, habia sido leida ante la Asamblea General de la ONU en octubre 1981 por el comandante Daniel Ortega. Para varios dirigentes del FSLN la firma de la declaración de San Isidro representó abandonar al FMLN en medio de la lucha, y obligó a Daniel Ortega y 
al Ministro de Defensa Humberto Ortega a una extensa justificación de las razones por las cuales el documento se firmó (Barricada 20 y 21 de diciembre 1989). ${ }^{\circ}$

Como agravante, las sucesivas concesiones de la diplomacia sandinista en el proceso de negociación regional fueron ineficaces para lograr el desarme y desmovilización de la contra. El "plan conjunto para la desmovilización, reubicación o repatriación voluntarias en Nicaragua y en terceros países de los miembros de la Resistencia Nicaragũense y de sus familiares", que de acuerdo al documento presidencial de Costa del sol debería elaborarse en un plazo máximo de 90 dias, cayó en saco roto, a pesar de las concesiones ya referidas del gobierno nicaragũense. De acuerdo al plan aprobado por los presidentes en Tela, la desmovilización, reubicación y repatriación voluntaria de la Resistencia Nicaragüense debia cumplirse completamente a más tardar el 5 de diciembre 1989, cosa que no ocurrió. En la reunión de San Isidro Coronado esa fecha se extendio al 5 de febrero, pero tampoco se cumplio.

Habria sido dificil que las cosas ocurrieran de otra manera, en la medida en que la desmovilización de la contra dependía no obviamente de la voluntad de los gobiemos centroamericanos, ni de las concesiones unilaterales del gobierno sandinista en materia de política interna y de política regional, sino ante todo de la voluntad política del gobienro de los Estados Unidos. Una circunstancia que siempre estuvo presente en el discurso político del sandinismo, pero que no se tradujo en acciones concretas ni previno el otorgamiento de las ya referidas concesiones.

Por anadidura, el calendario de las políticas referidas a la negociación regional y el proceso electoral dificultó el calendario de las politicas de ajuste. Cuando se inició el primer programa de ajuste en junio 1988 se esperaba contar con un margen de al menos dos anos antes del inicio de la campana para las elecciones originalmente fijadas en noviembre de 1990 . Se creía que después del impacto negativo inicial, se podría disponer de un ano antes de las elecciones para recuperar minimamente los niveles de vida de la población a través de una reactivación de la producción y el empleo, y pavimentar el camino hacia otros seis años de gobierno. Pero el adelantamiento del calendario electoral casi un ano por las razones ya senaladas redujeron ese tiempo a casi la mitad y dejaron a los tecnócratas de la economia en el infierno del corto plazo sin esperanzas del mediano plazo.

Los tiempos del giro a la derecha en economía chocaron con los tiempos del giro a la derecha en política interna y regional, y este con- 
flicto hizo imposible la recomposición, de todos modos problemática, del campo popular en visperas de las elecciones: precios libres y estómagos vacios no son buenos argumentos para ganar votos en favor de un gobierno. Las victorias antiinflacionarias y estabilizadoras que el sandinismo enarboló a principios de 1990 -reducción de las brechas externas, la hiperinflación (de más de $33,000 \%$ en 1988 a algo menos de $1700 \%$ en 1989) y el déficit fiscal (de $25 \%$ del PIB en 1988 a casi $5 \%$ en 1989), y un pequeno aumento de las exportaciones- significaron poco para una población que tuvo que pagar esos éxitos con un agudo deterioro de sus condiciones de vida y un $35 \%$ de desempleo y subempleo. Las promesas electorales del sandinismo de que "Todo será mejor", según rezaba la consigna de las aspiraciones reeleccionistas de Daniel Ortega, chocaron contra los efectos de las políticas que llevaban a la gente a pensar que nada podría ser peor...

\section{3. ¿Habla alternatlvas?}

El impacto desastroso de las políticas de ajuste en las condiciones de vida de las masas, su efecto desestabilizador para los gobiemos que las promueven, y su muy reducida eficacia para alcanzar las metas que se proponen, son de sobra conocidos. ¿Por qué entonces el sandinismo recurrió a ellas, cuando además era evidente que esas políticas se daban de patadas con las orientaciones de la mayorla de las metas revolucionarias? La explicación oficial plantea que no habla alternativas, que la desarticulación económica era de tal magnitud que no hubo más remedio que apelar a estas soluciones dolorosas: el pueblo sabria comprender.

La existencia de alternativas a una estrategia económica dada es una cuestión política y no solamente técnica. Además, cada decisión que se toma en un sentido cierra o reduce las altemativas que estaban abiertas para tomar decisiones en otro sentido, o las hace más difficiles. A fines de 1989 eran pocas las alternativas que existian al programa de ajuste, mientras que a mediados de 1988 las posibilidades eran más amplias, y en 1985 todavia mayores.

En lo que toca a la guerra, es claro que no habia alternativas. El enfrentamiento de Estados Unidos a la revolución fue decidido por el gobiemo de Estados Unidos, no por el de Nicaragua; tampoco hubo alternativas al terrible impacto de la guerra. Pero habia alternativas en el modo de encarar la guerra, en el diseno de las políticas económicas y sociales, en los estilos de relacionamiento con las organizaciones de masas, y en las modalidades de trabajo de éstas. Y lo mismo debe decirse en torno a la estrategia macroenómica de transformación y de- 
sarrollo. La estrategia de grandes inversiones estatales fuertemente dependientes de insumos importados y financiamiento externo, de maduración en el mediano y largo plazo, no contempló la hipótesis de una guerra contrarrevolucionaria ni el deterioro del sector externo -dos situaciones recurrentes en todos los procesos revolucionarios del siglo XX (Vilas 1988). Con la guerra los proyectos se vinieron abajo y la unidad nacional multiclasista empezo a resquebrajarse. En vez de reformularla, el sandinismo optó por incrementar los subsidios que nutrlan la permanencia de los exportadores y otros grupos propietarios, a costa obviamente de mayores presiones sobre las condiciones de vida de los trabajadores.

El sandinismo se enfrentó a una situación frecuente en política: las alianzas que en determinado momento permiten avanzar, en otro momento se convierten en obstáculos. Pero frente a ésto, cabe al menos una opción: romper los viejos acuerdos para superar los obstáculos y seguir adelante, 0 insistir en aquéllos con un costo social y político creciente, arriesgando al empantanamiento del proceso. Cuba es un buen ejemplo de la primera de las opciones (Vilas 1989a). El gobierno de Daniel Ortega en cambio optó por la segunda, apostando a que el mantenimiento de las alianzas iniciales, e incluso su mayor ampliación, permitirla arribar al fin del conflicto, reanudar el financiamiento extemo y reiniciar el proceso de transformación. Esto revela que en determinado momento también existió la posibilidad de optar por una de las dos maneras básicas de encarar la guerra: como un escenario definido por el imperialismo que puede ser convertido en un insumo para el avance revolucionario, o como un obstáculo que hay que desmontar para que, una vez alcanzada la paz, la revolución sea posible. Después de algunas idas y vueltas el sandinismo optó por el segundo enfoque (Wheelock 1983; Tirado López 1985).

El predominio de estos enfoques dentro del gobierno sandinista tiene que ver con el carácter pluriclasista del FSLN y con el peso creciente que sus elementos más ligados a las clases medias y a las fracciones antisomocistas de la burguesia conservadora fueron adquiriendo en la conducción del gobiemo durante la década de 1980. Esto se expreso en una primacla de los aparatos del estado sobre el partido de tal manera que con frecuencia funcionarios gubernamentales de menor nivel polftico partidario imponian sus decisiones a pesar de criterios opuestos de dirigentes sandinistas de mayor nivel. A pesar de todas las trivialidades escritas acerca de una presunta subordinació del estado al partido, en la Nicaragua sandinista el estado, más que el partido, era la fuente del poder. ${ }^{\circ}$ 
No se trata de una cuestión nueva. La lucha contra Somoza movilizó a amplios grupos sociales en los que impactó de manera negativa la modernización capitalista promovida por el somocismo: campesinos en vías de proletarización, agricultores, de la frontera agricola, asalariados urbanos, pequena burguesia. Pero también se sumaron segmentos de las clases más tradicionales, amenazadas por la "competencia desleal" del estado y marginados de la modernización capitalista (Vilas 1984); muchos de sus hijos ingresaron al FSLN, y arrastraron tras de sí a sus padres. Desde el principio estos elementos figuraron de manera prominente y abundante en los elencos del gobierno; lograron suspender la aplicación de los decretos 3 y 38 de la Junta de Gobierno que ordenaban la confiscación de las propiedades del somocismo, disenaron el enfoque desarrollista estatista de los anos iniciales de la revolución, y el frustrado intento de ajuste de 1985, y consiguieron mantener canales de diálogo y de negociación con segmentos del establishment político estadounidense. La historia de las politicas sandinistas es en buena medida la historia de las pugnas intemas entre estos sectores tecnocráticos emergentes de las familias más tradicionales de Nicaragua, y las iniciativas emanadas de orientaciones más próximas a las demandas del campesinado, los asalariados del campo y. la ciudad, la pequena burguesía, que pretendian consolidar las alianzas con estos grupos como forma de avanzar el proceso revolucionario a partir del escenario de guerra impuesto por la Casa Blanca, y más interesados en forjar alianzas con Europa oriental y occidental.

Con los enfoques de la relación clases/guerra y de la relación guerra/transformaciones revolucionarias predominantes en 1988, no era mucho lo que se podia hacer en términos de un enfoque alternativo de política económica. Por lo menos desde 1985 — vale decir bastante antes de la crisis del bloque socialista europeo- el sandinismo optó por privilegiar las buenas relaciones con la comunidad intemacional occidental para neutralizar las presiones del gobierno de Estados Unidos, pero sin una conciencia clara del precio que usualmente debe pagarse por ello en términos de reducir el ritmo y la intensidad de las transformaciones revolucionarias -una cuestión que este autor sefaló hace anos (Vilas 1986a).

Por lo tanto es correcto hablar de "falta de alternativas" a las políticas de ajuste, si por ello se entiende que, a mediados de 1988, las cartas ya estaban echadas en el terreno político a causa de las rigideces creadas por las decisiones previas, pero es equivocado si se quiere signifcar que no existian otras formas de encarar la recomposición de la economia. Existian otras formas, menos gravosas para el campesino y los asalariados del campo y la ciudad. A esta altura del 
desarrollo de los acontecimientos, habría sido una alternativa económica de un gran costo político en términos de las alianzas básicas del sandinismo, aunque seguramente no tan alto como el que pagó el 25 de febrero. ${ }^{10}$

Solamente un abismal aislamiento de las masas puede explicar que los sandinistas pensaran que con esa política económica, y en esas condiciones, podia irles mejor que a Raúl Alfonsin en Argentina o a Jorge Blanco en República Dominicana. No hubo en Nicaragua un "managuazo" equivalente al "caracazo" venezolano, pero hubo un "electorazo": la gente votó contra el FSLN y lo saco del gobierno.

\section{El impacto de las elecclones}

Las elecciones del 25 de febrero llevaron al gobierno a una coalición de fuerzas sociales y políticas heterogéneas, unidas por el común denominador del antisandinismo. Poco más de un mes después de la inauguración del nuevo gobierno, resulta claro que el objetivo central de su acción consiste en desmontar lo que ha sobrevivido del proceso revolucionario a la guerra y a las políticas de ajuste ejecutadas desde mediados de 1988 por el propio gobierno sandinista, y a la desmovilización social consiguiente.

\section{¿"Somocismo sin Somoza"?.}

Los decretos-leyes 10-90 y 11-90 del 11 de mayo 1990 han creado las condiciones jurídicas para el desmantelamiento de la reforma agraria y la liquidación del Area de Propiedad del Pueblo (APP). El primero de ellos, denominado "de arrendamiento provisional de tierras", concede en tal calidad las tierras aptas para agricultura o ganaderla propiedad del estado 0 administradas por cualquiera de sus instituciones en virtud de "decretos confiscatorios o expropiatorios o que hubiesen sido declaradas de utilidad pública y las que bajo cualquier otra forma arbitraria hayan sido confiscadas por el gobierno anterior o que estén en posesión de terceras personas sin ser sus legítimos duenos" (art. 1). El decreto desconoce por tanto la legalidad de las afectaciones de la reforma agraria y de la constitución del APP, con la sola excepción de "las propiedades rústicas confiscadas bajo los decretos № 3 de fecha 20 de julio 1979 y Ne 38 del 8 de agosto 1979" dictados por la Junta de Gobierno de Reconstrucción Nacional de la que dona Violeta formaba parte, y que convirtieron en bienes públicos las propiedades de la familia Somoza. Beneficiarios de esta medida son las personas naturales y juridicas que acrediten la propiedad de las tierras respectivas y asuman el "compromiso formal de cultivarlas o continuar haciéndolo de inmediato para aprovechar el presente ciclo agricola" (art. 2 inc. 5). 
El decreto-ley 11-90 "de revisión de confiscaciones" crea una Comisión Nacional de Revisión facultada para "procoder a la revisión do todas las confiscaciones ejecutadas por el gobierno anterior bajo las leyes y decretos confiscatorios, expropietarios o de Reforma Agraria y los que de una u otra forma privaron de sus bienes, derechos y acciones a personas naturales o jurídicas, respetando los derechos de los campesinos, de las cooperativas que cumplan su función social y económica y de las personas menos privilegiadas" (art. 1). En estos casos excepcionales el estado pagará indemnización en obrdobas oro (la moneda progresivamente introducida por el nuevo gobierno) a los reclamantes insastisfechos (art. 12) "La resolución de devolución servirá como suficiente título para ejercer el derecho pleno sobre los bienes, derechos y acciones reclamados" (art. 11). La excepción de los bienes afectados por los decretos 3 y 38 de 1979 no se aplica a la revisión de confiscaciones, de modo que también los funcionarios de somocismo y los miembros de la familia somoza podrán hacer sus reclamaciones.

Inmediatamente después de asumir la presidencia dona Violeta anunció la suspensión del servicio militar y emitió un decreto de amnistia amplia en beneficio de todos quienes abandonaron el territorio de Nicaragua después del 19 de julio 1979. Los funcionarios y socios del somocismo han comenzado a regresar ya a Nicaragua. Anastasio Somoza Portocarrero, hijo del dictador, director de la Escuela de Entrenamiento Básico de Infanterias (EEBI) donde se formaba a los elementos más nefastos de la Guardia Nacional, y sospechado de ser el autor intelectual del asesinato del periodista y político Pedro Joaquín Chamorro (esposo de dona Violeta) en una acción que detonó el tramo final de las luchas populares, anunció su próximo retorno a Nicaragua, beneficiado también él por la generosa amnistia.

Valiéndose de la mayoria absoluta en la Asamblea Nacional, el nuevo gobierno ha procedido a dejar sin efecto la legislación sancionada 0 reformada por el gobierno sandinista entre el 25 de febrero y el 24 de abril. Han caido hasta el momento las reformas al código del trabajo y la ley de servicio civil, y están bajo la mira la ley de autonomia universitaria. Los convenios colectivos de trabajo están siendo sometidos a revisión y desde el Ministerio del Trabajo se está auspiciando la formación de sindicatos paralelos con los que desarrollar las negociaciones laborales. Enfrentado el sandinismo ante el hecho inverosimil de la derrota electoral, se embarcó después del 25 de febrero en una intensa actividad legislativa tratando de hacer en los dos meses que le quedaban de gobiemo varias de las cosas que no habia hecho en los once anos anteriores. Durante esos anos el movimiento sindical no pudo 
conseguir la sanción de un nuevo codigo de trabajo; en todo el periodo siguió rigiendo el código sancionado en la década de 1940 durante el gobierno del primer Somoza. El sandinismo adujo la inexistencia de condiciones para tal reforma, y las garantlas politicas que la clase obrera tenla de que sus articulos más regresivos - por ejemplo, la posibilidad de despedir sin aviso previo a un trabajador-, jamás serlan aplicadas por el gobierno revolucionario. Del mismo modo hubo oposición gubernamental a sancionar una ley de autonomla universitaria ¿como podla pensarse en una universidad autónoma del estado popular? Los ejemplos podrlan extenderse. Las modificaciones efectuadas por la Asamblea Nacional bajo mayorla de la UNO han retrotraldo la situación a su estado anterior, pero con un gobierno que si está dispuesto a aplicar los aspectos más anti obreros y anti populares de aquella legislación.

Por su parte el Ministerio de Educación ordenó remplazar los libros de texto de educación básica (hasta cuarto ano de ensenanza primaria) por textos preparados por la Agencia Internacional de Desarrollo (AID) del gobierno norteamericano... para el gobierno de Honduras. Se ha prohibido el uso de minifaldas en las oficinas gubernamentales tanto empleadas corno a usuarias; se aconseja a los hombres el uso del saco y la corbata, o de guayabera en su defecto, y se recomienda sustituir el trato irrespetuoso de "companero" y "companera" por el más formal de "senor", "senora" o, si aplica, "senorita".

El triunfo de la jerarquía de la iglesia católica es notorio. La situación de las comunidades de base, que reclutan a sus adherentes más en las ciudades - Managua ante todo-que en el campo, y más en la pequena burguesia que en la clase obrera y el campesinado, es precaria. El sandinismo militante que ostentaron no se tradujo en resultados electorales, y ahora deberán pagar su enfrentamiento a la jerarqula y su exaltación acrítica -muy parecida a la posición de iglesia respecto del somocismo en la etapa pre-sandinista- del régimen derrotado. Si alguien es el vencedor neto de toda esta compleja y dramática historia de revolución y contrarrevolución, ése es monsenor Obando. La Conferencia Episcopal de Nicaragua, cuyos miembros tienen una larga lista de cuentas por cobrarle al sandinismo -el "caso Carballo", la expulsión de sacerdotes por su involucramiento en actividades opositoras, las sanciones contra el obispo Vega por su colaboración con la contra, las sanciones contra radio Católica, los coqueteos del gobierno sandinista con los predicadores evangélicos de Estados Unidos, el apoyo de Daniel Ortega al "congreso de brujos" de febrero 1990, etc.emitio el 6 de junio una declaración de apoyo al gobierno de dona Violeta, reclamando una amplia derogación de las leyes sancionadas por 
el sandinismo por atentar contra la democracia y el bien común.

A los contras les ha ido hasta el momento particularmente bien. A pesar de los compromisos firmados con el nuevo gobiemo, el proceso de desmovilización se desenvuelve lentamente y el 10 de junio, fecha en que según lo formalmente acordado debla haberse completado, todavia un tercio de los efectivos se mantenia armado. Han obtenido del gobiemo la concesión de un territorio de unas 2,000 hectáreas que abarca casi todo el departamento de Río San Juan e inchye la ribera del río San Juan hasta su desembocadura en el Atlántico. En ese "polo de desarrollo" recibirán asistencia económica del gobiemo y ejercerán su propia autoridad, incluyendo un cuerpo policial formado y ammado por ellos mismos. En este último respecto debe sehalarse que el 10 de junio los efectivos desmovilizados sólo hablan entregado armamento liviano, conservando en su poder una importante dotación de cohetes tierra-aire ("red eye"), canones sin retroceso de $57 \mathrm{~mm}$ y morteros de $81 \mathrm{~mm}$.

La ubicación geográfica del territorio adjudicado a los contras, fronterizo con Costa Rica y con la costa del Atlántico próxima a la isla colombiana de San Andrés, las condiciones ecológicas, y la vigilancia armada de los propios contras, sugieren a algunos observadores que los desalzados habrán de dedicarse al próspero negocio de la narco agricultura. Asimismo algunos dirigentes han anticipado su decisión de constituir su propio partido político, que aspira a reclutar adherentes incluso entre los desmovilizados del EPS, sobre la base del denominador común de los que, desde uno u otro bando, pelearon la guerra durante los antos pasados, por oposición a los que, también en uno y otro bando, dirigieron la guerra desde Managua o desde Miami. Una convocatoria política que apela a identidades sociales, étnicas y culturales básicas y que puede llegar a alcanzar amplias resonancias.

La política económica ejecutada hasta ahora guarda continuidad con la que el sandinismo venia aplicando desde mediados de 1988 -algo que este autor anticipó antes incluso de las elecciones de febrero (Vilas 1990b): liberación de precios, restricciones crediticias, devaluaciones sucesivas, etc. Las cooperativas y el campesinado excluidos 11-90 están sufriendo los embates de la política crediticia y de precios, y del mercado. Habrá que ver, dentro de dos o tres anos, cuántos pueden cumplir con su Tunción social y económica" y siguen al frente de sus tierras. El lanzamiento hacia un nuevo plan de ajuste y a intentos serios de reactivación económica dependen de la resolución de la cuestión de la deuda externa de un monto acumulado de $\$ 10,000 \mathrm{mi}$ llones, y del acceso a fondos externos - una crónica carencia del 
régimen sandinista. Hasta el momento el gobierno de dofa Violeta ha conseguido \$300 millones de ayuda de emergencia aprobada por el gobiemo de Estados Unidos, que rápidamente levantó las sanciones oconómicas que aplico al gobiemo sandinista, y $\$ 120$ millones obtenidos en la conferencia intemacional de donantes celebrada a principios de junio en Roma. Si se compara esta suma con bs modestos $\$ 50$ millones obtenidos por el gobiemo de Daniel Ortega en una conferencia similar en Estocolmo en mayo 1989, es evidente que las más amplias simpatias de la comunidad intemacional hacia el gobiemo de dona Violeta se traducen en plata.

Contra las previsiones de sandinistas y de observadores, el nuevo gobiemo está decidido a revertir $b$ antes posible las instituciones y muchas de las conquistas de la revolución, y aún tiene seis anos por delante. Resulta evidente la fragilidad de esas instituciones y conquistas, una vez que el gobiemo sandinista cayó. En último análisis, el objetivo del nuevo gobiemo es poner a Nicaragua en las condiciones sociopoliticas en que se habrla encontrado en 1978 si Anastacio Somoza hubiera aceptado las presiones de Estados Unidos y se hubiera marchado: un "somocismo sin Somoza" en su acepción más literal y restrictiva. El programa del nuevo gobierno - no el que abono su campana electoral, sino el que esta ejecutando efectivamente- es de contenido y alcance contrarrevolucionario, en el sentido literal de ir contra las realizaciones de la revolución, aunque no haya habido en Nicaragua una invasión como en Guatemala en 1954, o un golpe de estado como en Chile en 1973. Se trata de desmontar todo lo que es producto o consecuencia del modo revolucionario en que hubo que deshacerse de la dictadura somocista. Las diferencias dentro del nuevo gobierno - por ejemplo, entre el grupo de asesores más próximo a dona Violeta, el gnupo "duro" del vicepresidente Virgilio Godoy, y los elementos más claramente ligados al somocismo capitaneados por el alcalde de Managua - se refieren más a estilos y modalidades de acción, que a los alcances o el contenido del programa.

\section{La situación del sandlnlsmo}

Después de once anos de ejercicio del gobierno y de control exclusivo de los recursos del estado, el sandinismo está encontrando problemas para disenar una política opositora definida. La hipótesis sandinista de conflictos internos dentro de la UNO a partir de los cuales aplicar una política de dividir y reinar, negociando la permanencia de las principales instituciones de la revolución con el gnupo de asesores más próximo a dona Violeta -muchos de ellos ex sandinistas, y ligados por estrechos lazos de familia a dirigentes y funcionarios del 
sandinismo- ha resultado hasta ahora desafortunada. A pesar de sus evidentes tensiones y diferencias internas, la UNO se ha comportado de manera unida para desmontar logros e instituciones de la revolución, y dona Violeta ha recurrido a las amplias facultades presidenciales reconocidas por la constitución política de 1987 -aprobada por el sandinismo- cada vez que podia preverse de la existencia de resistencias o diferencias de criterio dentro de la bancada oficialista en la Asamblea Nacional que pudieran amenazar su mayoría absoluta.

A poco más de un mes del cambio de gobiemo, el FSLN proyecta una imagen ambigua en su papel de principal partido de oposición, tensionado por una doble posibilidad: optar por un pertil negociador, adoptando el rol de interlocutor constructivo en nombre de una nación nicaragũense y una democracia concebidas al margen de las tensiones y contradicciones sociales y de los proyectos en función del carácter antipopular $e$ incluso revanchista de las principales medidas adoptadas hasta ahora por el gobierno de la UNO.

El masivo y en buena medida espontáneo movimiento huelguistico de mediados de mayo en oposición a las medidas regresivas mencionadas más arriba, que amenazó con paralizar completamente el país, ilustra el estado de ánimo de amplios sectores de población -incluyendo posiblemente a mucha gente que votó por la UNO- ante medidas que golpean directamente importantes logros de la revolución, aunque muchos de ellos hubieran sido duramente golpeados por las políticas sandinistas de ajuste: estabilidad en el empleo, libertad sindical, acceso a una canasta básica de consumo. La oleada de huelgas mostró un nivel de activación de masas del que no habia precedentes desde la época de la insurrección antisomocista. Por otro lado, la participación del ex vicepresidente Sergio Ramirez en la misión del gobierno de Nicaragua a la conferencia de donantes celebrada a principios de junio en Roma, para fortalecer las demandas de cooperación externa, ilustra la insistencia sandinista en ofrecer una imagen externa de madurez y colaboración en nombre de la nación, aunque en concreto resulte en afianzar a un gobierno que ha erigido en objetivo central la liquidación de la revolución sandinista.

Hasta el momento la estrategia negociadora ha rendido pocos frutos, si algunos, al sandinismo. La importancia asignada por el FSLN a la permanencia de muchos de sus altos cuadros en cargos estatales - secretarios generales y directores en varios ministerios, el ministrodirector del Instituto Nicaragūense de Energia, el jefe y mandos superiores de la Policia, además del caso ya citado del ejército-, no tiene conrrelato en la capacidad de estos funcionarios para modificar el 
contenido o los alcances de las políticas efectivamente ejecutadas por el gobierno de la UNO. La permanencia del general Humberto Ortega y de los mandos superiores del ejército al frente del Ejército Popular Sandinista (EPS), llevada a cabo a costa de sus renuncias a los cargos que ostentaban en las estructuras partidarias del FSLN - en el caso de Ortega, a su condición de miembro de la Dirección Nacional del FSLN - tuvo como explicación la necesidad de mantener la conducción militar hasta que la contra se desmovilizara completamente. Ya hemos sefalado la lentitud del proceso de desmovilización, y en todo caso la permanencia de estos sandinistas al frente del ejército no ha impedido hasta ahora el agudo contraste entre los beneficios obtenidos por los contras -derrotados en el terreno militar-, y los soldados desmovilizados del EPS, abandonados a su propia suerte.

Esta última cuestión puede convertirse en un factor de fuerte desestabilización política y social. Los ejércitos desmovilizados siempre plantean problemas a los gobiernos, especialmente los ejércitos militar - moralmente derrotados. EI EPS venció militarmente a la contra, pero las condiciones diferenciales de desmovilización de uno y otra convierten a la segunda en triunfadora moral, en todo caso en vencedora política. Los contras dispondrán de territorio, crédito, facilidades, y sin dudas la preferencia oficial. Los desmovilizados del EPS tendrán que hacerle frente a una economía en crisis y a políticas crediticias restrictivas, que ofrecen pocas si alguna posibilidad de reinserción productiva, y disuaden expectativas de progreso. La experiencia de los afectados por las reducciones presupuestarias del EPS y el Ministerio del Interior en 1989 son ilustrativas para esta nueva oleada de desempleados. Las condiciones para el surgimiento de reacciones de resentimiento y f́nstración están abiertas, especialmente para los reclutas, suboficiales y oficiales que durante la guerra fueron asignados a las posiciones de mayor riesgo y mayor exposición al combate.

Existen muchas anécototas y evidencias aisladas de (¿ex?) sandinista afectados por estas medidas, que en las elecciones de febrero votaron por la UNO; un voto inspirado por el resentimiento, antes que por la esperanza. Es previsible que el proyecto de algunos elementos de la dirigencia militar de la contra, de organizar un partido político que competiria en las elecciones presidenciales de 1996, y que reclutaria a sus adherentes entre los ex combatientes de uno y otro bando, sus familiares, relaciones y ámbitos de vida comunitaria -por oposición a los dirigentes de uno y otro bando a quienes se acusa de haber pasado una buena vida de oficinas, hoteles y recepciones-, encuentre en muchos desmovilizados del EPS y sus familias, ofdos receptivos. Algo asi como el partido de los pobres, de los plebeyos, de los mes- 
tizos, de los campesinos, de los que se jugaron por encima de las banderas "impuestas" por los sehores cultos, ricos, blancos, de uno y otro bando, parientes entre sí, y titulares de casi todas las estructuras institucionales del estado antes y ahora." En todo caso el contraste entre la habilidad de los dirigentes de la contra para asegurar a su gente una desmovilización digna, y las condiciones duras de los desmovilizados del EPS, a pesar de que todos sus más altos oficiales retienen sus posiciones de mando, habrá de generar efectos políticos.

La ambigũedad en el perfil opositor del FSLN testimonia una vez más la coexistencia de enfoques y tendencias heterogéneas en el seno de una organización policlasista tensionada por una mezcla de inclinaciones socialdemocratas, marxistas, nacional-revolucionarias y tecnocrático-desarrollistas -una cuestión a la que me he referido anteriormente (Vilas 1989a).

\section{Consideraclones finales}

Hacia principios de 1990 para una parte grande de la población nicaragũense que en anos anteriores habia apoyado o mirado con simpatía al sandinismo, no era mucho lo que quedaba de revolución.

Una política exterior que viraba hacia la derecha sin por ello conseguir la desmovilización de la contra ni sensibilizar a la comunidad financiera internacional; la libertad de los militares somocistas; la política oconómica de concesiones a los grupos dominantes y deterioro de las de por si degradadas condiciones de vida de las masas; retrocesos en materia de reforma agraria, salud y educación; endeudamiento del campesinado; inflación y desempleo. Un sandinismo que denunciaba la presencia de somocistas dentro de la Unión Nacional Opositora (UNO) pero que al mismo tiempo creaba las condiciones institucionales para esa presencia y, para ganar los votos de la derecha y mejorar la imagen intemacional, llevaba a cabo anticipadamente las reivindicaciones planteadas al respecto por la UNO - ante todo la libertad de los somocistas condenados por crimenes y violaciones a los derechos humanos. $Y$ frente a todo esto, el gobierno de Estados Unidos que mantenía inalterada su retórica agresiva, prolongaba ano tras ano el embargo económico, bloqueaba la desmovilización de la contra, y apoyaba abiertamente la candidatura antisandinista de dona Violeta Barrios de Chamorro, que prometía la abolición del servicio militar ya mismo y anunciaba un programa económico que en los papeles no lucía peor que el que Daniel Ortega estaba ejecutando.

La incapacidad de la revolución sandinista de avanzar por encima de los límites de su etapa inicial de alianza amplia de grupos y clases 
sociales, dio mayor visibilidao a sus limitaciones ulteriores, a los compromisos celebrados hacia la derecha y con la comunidad internacional, al fortalecimiento de los estilos políticos tradicionales prebendalista y burocráticos, y al peso creciente en las decisiones del gobiemo y del FSLN de sus elementos más ligados a los grupos medios y empresariales; factores todos que desorientaban a las bases sin garantizar la lealtad de las élites ni la benevolencia del gobiemo de Estados Unidos.

Para algunos, los sandinistas estaban deshaciendo to que hicieron al principio de la revolución; para otros, estaban recomponiendo tardiamente lo que destruyeron. Estas idas y vueltas desde afuera y desde arriba de las masas, que eran las perdedoras netas del juego sandinista, alimentaron el voto del domingo 25 de febrero. No es la primera vez en la historia de la revolución que la gente hace sentir su rechazo a lo que estima como retrocesos y errores del gobierno, virándose hacia sus enemigos e incluso colaborando con los contras. Lo hicieron los campesinos de Jinotega y de Matagalpa a mediados de los 80s, y los indios y los creoles de la Costa Atlántica. Entonces, el sandinismo captó el mensaje y reorientó sus políticas en el sentido de las demandas populares.

En 1990 la contra estaba militarmente derrotada y su dirigencia política incorporada al proceso electoral; todo el mundo estaba harto de guerra y de violencia, y las grandes movilizaciones en nombre de la revolución popular pertenecian al pasado. En las elecciones de 1984 los nicaragüenses eligieron entre la revolución y la contrarrevolución. En las elecciones de 1990 se eligió entre la continuidad de un régimen cuyas resonancias revolucionarias pertenecian casi enteramente al pasado, y las promesas de cambio emergentes de lo desconocido.

A medida que la negociación internacional se desarrollaba, que la contra no se desmovilizaba, y la crisis económica se profundizaba, la opinión pública internacional fue siendo erigida por el gobiemo sandinista en su interlocutor principal, desplazando a las opiniones, las iniciativas y las demandas de las masas. Una opinión pública internacional que en términos concretos estaba integrada por las fuerzas políticas conservadoras de Centroamérica, por gobiernos europeos sin interés alguno en deteriorar sus relaciones con Estados Unidos por culpa de los sandinistas, por elementos de la política norteamericana preocupados ante todo por su propia fortuna electoral y por los entusiastas pero politicamente intransitivos grupos de solidaridad. Todos empenados - con la posible excepción de estos últimos- en convencer a los sandinistas de los beneficios de una democratización enten- 
dida como menos revolución, no como más participación.

La estrategia de negociación internacional para sobrevivir a la guerra y sus efectos, la recomposición de las alianzas internas y la proyección de una imagen más grata a los interlocutores externos, tuvieron asi como precio la desaceleración de la revolución, la inversión de sus políticas económicas y la reversión de muchas de sus conquistas sociales y políticas. En los tramos finales de la campana electoral, la competencia por los votos de las clases medias y los grupos propietarios difundió en las masas la imagen de un sandinismo que prometia cualquier tipo de concesiones hacia la derecha y hacia afuera como forma de mantenerse en el ejercicio del gobiemo, pero sin poder garantizar, a cambio de esas concesiones, el desarme de la contra o una mejoria económica. Habiendo derrotado militarmente a la contra pero sin capacidad para desmantelarla, el sandinismo optó por enfrentarse al gobierno de Estados Unidos apelando a una estrategia de menos revolución que le permitió ganar el aplauso alborozado de sus enemigos, y perder el gobierno por el repudio electoral de una parte importante de su pueblo.

¿Qué sobrevivirá de la revolución sandinista en 1996? la respuesta depende en buena medida del modo en que se conceptualice a la revolución. Si la revolución sandinista se reduce a las instituciones estatales y a las transformaciones sociales y políticas articuladas a esas instituciones, pocas dudas caben que el gobierno de la UNO cuenta con recursos institucionales, con tiempo y con apoyo externo suficientes para revertir la situación de Nicaragua a la de antes del sandinismo. Si en cambio se presta atención a los desarrollos organizativos y de movilización de las masas, a sus experiencias de participación y de lucha, las cosas no están tan claras, y el desmontaje de la revolución será una tarea más complicada y de éxito más dudoso.

A pesar de las restricciones que el estado trató de imponerles en aras de la concertación con los empresarios, los trabajadores cuentan hoy con una conciencia y una práctica de los derechos laborales inexistentes hace once anos. No obstante la desaceleración de la reforma agraria en los anos finales del gobiemo sandinista como parte de la estrategia electoral de captación de votos de los sectores medios y terratenientes, el campesinado adquirió un acceso a recursos y a organización productiva sin paralelo en Centroamérica. Una década de sandinismo ha desarrollado un sentido de eficacia politica de la participación popular que constituye uno de los activos más importantes de este periodo. Esa participación no fue una dádiva del estado revolucionario, sino que la gente la ganó luchando contra el somocismo y a veces 
también contra los aparatos del propio estado revolucionario.

La diferenciación apuntada entre las orientaciones negociadoras de la conducción sandinista, y el clima de belicosidad de masas, constituye una nueva ilustración de las tensiones existentes dentro del campo sandinista en la etapa abierta tras las elecciones de febrero. Del modo en que esta tensión se resuelva en el futuro próximo dependen en definitiva las perspectivas de resistencia ante los embates liquidacionistas del gobierno de Violeta Chamorro, y de pervivencia del sandinismo como una altemativa popular efectiva en Nicaragua.

\section{Notas}

1. Argentino, especializado en estudios del desarrollo. Investigador Titular, Centro de Investigaciones Interdisciplinarias en Humanidades, Universidad Nacional Autónoma de México. Vivió y trabajó en Nicaragua desde 1980 hasta 1990.

2. Vid la entrevista al ministro de Finanzas en Barricada, 6 de febrero 1989 $y$ el editorial de este mismo periódico: "No es justo, pero es imprescindible" (3 de febrero 1989); también la entrevista al Ministro de Cooperación Externa y miembro de la Dirección Nacional del FSLN, donde se hace un intento de explicación marxista de la estrategia de ajuste: Barricada 24 y 25 de febrero 1989.

3. En entrevistas con campesinos cooperativizados de Río San Juan en abril 1989 el autor encontró casos en que la deuda bancaria se había incrementado en el curso de cinco o seis meses entre $600 \%$ y $800 \%$ a causa de las elevadas tasas de interés y su indización a la tasa cambio.

4. El caso más sorprendente fue el de la cooperativa ganadera "Juan José Urbina" en la Región III, cuyas tierras fueron devueltas por MIDINRA a su anterior propietario Mario Hanon, posiblemente el más grande productor de arroz de Nicaragua, quien a fines de 1980 estuvo involucrado en actividades contrarrevolucionarias. Celebrando la decisión, el Sr. Hanon declaró que dados los precios bajos del arroz —un ingrediente básico de la dieta nicaragüense- iba a dedicar esas tierras a producir sandías para exportarlas a costa Rica, Vid. El Nuevo Diario, 1 de abril 1989, y Barricada, 13 de abril 1989.

5. Un ejemplo particularmente gráfico es el del administrador de una empresa estatal de la industria láctea, a quien en premio a su desempeño se le adjudicó un vehículo, pagado por la empresa, para su uso personal. Puesto que el funcionario ya era dueño de un auto, solicitó a la corporación de la cual depende la empresa que el nuevo fuera puesto a nombre de su hijo - a la sazón un muchacho de 14 años-, solicitud que fue concedida. Meses más tarde, el mismo funcionario solicitó a la corporación que, como estaba enviando a su hijo a estudiar al exterior, la empresa comprara el auto, y que la operación se efectuara en dólares, ya que como buen padre, debía proveer al mantenimiento de su hijo en el 
exterior, donde la moneda nicaragüense no circula. La solicitud también fue aceptada. Vid Barricada, 31 de enero 1989. La situación fue denunciada por el sindicato de la firma, sin mayores resultados prácticos.

6. Vid. los discursos del presidente Ortega presentando el programa de ajuste de junio 1988 (Barricada, junio 15, 1988), en ocasión del LX Aniversario de la revolución (Barricada, 20 de julio 1988), el informe a la Asamblea Nacional del 30 enero 1989 (Barricada, enero 31, 1989), y Ortega 1989. El nuevo discurso oficial impactó en algunos sectores de la iglesia católica, que a partir de él dieron por sentado sin más el caracter socialista de la experiencia sandinista: vid. IHCA 1989; Gorostiaga 1989.

7. Una encuesta efectuada en octubre 1989 por el Instituto Nicaragüense de Opinión Pública (INOP) en barrios populares de Managua reveló que 60\% de los entrevistados no participaba en actividades de desarrollo comunal; otro tanto manifestó no tener interés en politica.

8. EI FMLN rechazó "con indignación" el documento, mientras que la URNG guatemalteca expresó su "insatisfacción, preocupación y sorpresa". Vid respectivamente Crónica (Managua) Ne 57 (14-20 diciembre 1989) y El Nuevo diario 30 de diciembre 1989. En cambio, la URSS expresó su satisfacción: Barricada,14 de diciembre 1989. La firma de Daniel Ortega en la declaración de presidentes centroamericanos en Montelimar en las postrimerlas de su mandato (3 de abril 1990), que decidió "invitar fraternalmente al Gobierno de Panamá a participar en forma activa en los procesos de diálogo, negociación y concertación" centroamericana -vale decir, al gobierno impuesto por la invasión militar norteamericana a Panamá tras bombardeos masivos a la población civil de ese pais - fue otro regalo de la diplomacia nicaragüense a la línea más pro norteamericana en la politica regional.

9. Una ilustración de esto es el reportaje al Comandante de la revolución Luis Carrión Cruz, miembro de la Dirección Nacional del FSLN, donde reconoce su incapacidad como ministro de Economia e Industria de modificar las políticas de créditos e impuestos definidas desde la Secretaria de Planificación, el Banco Central y el Ministerio de Finanzas -a cuyo frente se encontraban funcionarios de menor nivel partidaria- que llevaba a la ruina a la industria nacional: vid Barricada, 3 de mayo 1989.

10. Un desarrollo de este tema excede los alcances de este articulo. Una presentación suscinta puede verse en Vilas 1989c; también APEN 1988.

11. Señalemos a título meramente ilustrativo que el industrial Antonio Lacayo Oyanguren, ministro de la Presidencia y yerno de doña Violeta, es primo hermano del general Joaquín Cuadra Lacayo (jefe del Estado Mayor del EPS), del coronel Osvaldo Lacayo Gabuardi (segundo jefe del Estado Mayor) y de la esposa del Comandante de la Revolución y miembro de la Dirección Nacional del FSLN, Luis Carrión Cruz (sobrino por parte de madre del ex dirigente de la Resistencia Nacional, Arturo Cruz Porras). Una hermana del nuevo ministro de Agricultura, Roberto Rondón, es casada con el comandante Victor Tirado López, también miembro de la DN del FSLN. 


\section{Referenclas}

pen, Asociación de Profesionales de la Economla Nicaragüense 1988. Breve evaluación de las politicas de 1988 y propuesta para 1989. Managua, diciembre (mimeografiado).

astro, Fidel 1990 "Comparecencia para informar al pueblo sobre su visita a Brasil. Ciudad de La Habana, 23 de marzo". En Fidel en Brasil. Selección de intervenciones. La Habana: Editora Polltica.

lerra, Centro de Investigaciones y Estudios de la Reforma Agraria 1989. Situación de los precios relativos en la producción campesina. Managua, febrero (mimeografiado).

agleburger, Lawrence 1990. Us Assistance to Panama, Nicaragua. Statement by Deputy Secretary before the Foreign Operations Subcommittee of the Senate Appropriations Committee. March 20, Washington D. C. US Department of State, Bureau of Public Affairs, Washington D. C.

iorostlaga, Xabler 1989. "Legados, retos y perspectivas del sandinismo 19791989". Nueva Sociedad 104 (noviembre-diciembre 1989) 24-39.

ICA, Instituto Histórico Centroamericano "Hacia donde vamos?". Envio, edición especial para el Décimo Aniversario de la revolución Sandinista. Julio $1-51$.

unta de Goblerno de Reconstrucción Naclonal 1983. Lineamientos de polltica económica 1983-1985. Managua.

unez, Orlando y Roger Burbach 1987. Revolución y democracia en la Américas. Managua: Editorial Vanguardia.

intega, Danlel 1989. "Construyendo el socialismo nica". Entrevista en Pensamiento Propio, julio.

llarte, Rene et al 1988. "Reforma económica: Hacia nuevas contradiociones". Boletín Socioeconómico de INIES 9 (septiembre-octubre) 3-12.

'amlrez, Serglo 1988. "Habrá elecciones aunque no haya paz". Entrevista en Pensamiento Propio 52 (julio-agosto) 5-9.

Irado López, Vletor 1985. La primera gran conquista: la toma del poder político. Managua: Ediciones de la CST.

llas, Carlos M. 1984. Pertiles de la revolución sandinista. La Habana: Casa de las Américas.

985 -Unidad nacional y contradicciones sociales en una economía mixta: Nicaragua 1979-1984". En Richard Harris y Carlos M. Vilas (comps.), La revolución en Nicaragua. México: Ediciones ERA, 17-50.

986e "Nicaragua: The fifth year -transformations and tensions in the economy". Capital \& Class 28 (Spring) 105-138.

986b "Sobre la estrategia económica de la Revolución Sandinista". Desarrollo Económico 101 (abril-junio) 121-142.

986c "The Mass Organizations in Nicaragua: The Current Problematic and Perspectives for the Future". Monthly Review 38 (6), november, 20-31.

986d "El impacto de la transición revolucionaria on las clases populares: la 
clase obrera on la revolución sandinista:. Cuadernos Pollticos 48 (octubre-diciembre) 92:114.

1987 "Socialismo en Nicaragua?". Nueva Sociedad 91 (septiembre-octubre) 159-175.

1988 War and revolution in Nicaragua". In Ralph Miliband, Leo Panitch and Jonh Saville, socialist Register London: Merlin Press, 182-219.

1980a Transición desde el subdesarrollo. Caracas: Editorial Nueva Sociedad.

1989b State, Class \& Ethnicity in Nicaragua. Boulder Co. \& London; Lynne Rienner Publishers.

1989 c "Crisis, ajuste y perspectivas de reactivación económica en Nicaragua". Polérnica (segunda Epoca) 9 (septiembre-diciembre) 22-31.

1990 "Especulaciones sobre una sorpresa: las elecciones en Nicaragua". En América Latina a la hora de las elecciones, México: Instituto Mora.

$1990 b$ "Las elecciones en Nicaragua", La Jomada (méxico) 23 de febrero 1990.

Wheөlock, Jalme 1983. El gran desafío. Managua: Editorial Nueva Nicaragua. 